\title{
Giant congenital pigmented nevi of the face: Operative management and risk of malignancy
}

\author{
Ronald M Zuker MD FRCSC FACS, Thomais G Iconomou MD, Bryan Michelow MD \\ Division of Plastic Surgery, The Hospital for Sick Children, Toronto, Ontario
}

\begin{abstract}
RM Zuker, TG Iconomou, B Michelow. Giant congenital pigmented nevi of the face: Operative management and risk of malignancy. Can J Plast Surg 1994;3(1):39-44. Giant congenital pigmented nevi of the face are rare but of major consequence. Complete early excision of these lesions is recommended not only because of the cosmetic deformity they impose but also because of their life threatening potential for malignant transformation. At the Hospital for Sick Children in Toronto 19 patients with giant congenital nevi of the face were reviewed. The anatomical location of the lesions, their morphological and histological characteristics, and the authors' experience with surgical management of these lesions were evaluated. The risk of malignancy arising from these lesions was also evaluated. In this study, one patient died of leptomeningeal melanocytosis associated with her giant congenital nevus of the face. Although an accurate incidence of malignant transformation has not been determined, the risk of malignancy in congenital giant facial nevi must be considered.
\end{abstract}

Key Words: Giant congenital pigmented nevi, Malignancy

\begin{abstract}
Naevi géants congénitaux pigmentés du visage : traitement chirurgical et risque de néoplasie
RÉSUMÉ : Les naevi géants congénitaux pigmentés du visage sont rares, mais peuvent avoir des conséquences graves. L'excision précoce et complète de ces lésions est à recommander, non seulement à cause de la difformité qu'ils occasionnent, mais également à cause du risque qu'ils posent à l'égard d'une néoplasie. Au Hospital for Sick Children de Toronto, 19 patients atteints de naevi géants congénitaux du visage ont été passés en revue. La localisation des lésions, leur morphologie et leurs caractéristiques histologiques, ainsi que notre expérience du traitement chirurgical de ces lésions, sont passées en revue. Le risque de néoplasie propre à ces lésions a également été mesuré. Dans cette étude, une patiente est décédée de mélanocytose leptoméningée associé à son naevus géant congénital du visage. Bien que l'incidence précise des néoplasies n'ait pas été déterminée, le risque lié aux naevi géants congénitaux du visage est à considérer.
\end{abstract}

A lthough giant congenital nevi of the face are rare lesions, they present a major challenge to the plastic surgeon. The diagnosis of 'congenital nevus' is made from the presence at birth of cutaneous nevocytes or melanocytes which form a pigmented lesion. Pathologically, they are nearly always reported to be intradermal or compound nevi, often associated with multiple small nevi in other areas of the body. Café-au-lait spots, mesenchymal tumours (fibromas, lipomas), Von Recklinghousen's disease, vascular nevi and other skin anomalies are often found in conjunction with facial nevi (1-5) .

The giant congenital melanocytic nevus is a rare neuroectodermal lesion occurring in approximately one of every 20,000 newborns $(4,6)$. The occurrence of giant congenital nevi of the face is even rarer, and can involve a variety of

Correspondence and reprints: Dr Ronald M Zuker, Head, Division of Plastic Surgery, The Hospital for Sick Children, Room 1524,

555 University Avenue, Toronto, Ontario M5G 1X8. Telephone (416)

598-1202, Fax (416) 813-6147 sizes and facial distribution. A great deal of controversy exists about the definition of 'giant'; proposed definitions have included: involvement of a major portion of the face, an area larger than the patients palm, involvement being larger than $900 \mathrm{~cm}^{2}$, with the largest diameter being at least $20 \mathrm{~cm}(8)$; a percentage of body surface area (9); an area impossible to excise without a significant deformity (10); or any lesion that precludes complete excision and primary closure of the defect in a single operation $(11,12)$.

Although it is well documented that giant pigmented nevi undergo malignant transformation, the incidence varies in the literature and has not been determined precisely. The relation between giant congenital nevi of the face and leptomeningeal melanoma is of particular clinical importance (13-16). We reviewed giant congenital pigmented nevi of the face to assess the distribution of the lesions and evaluate our experience in their surgical management. An attempt is made to investigate the risk of malignancy arising from these lesions. 


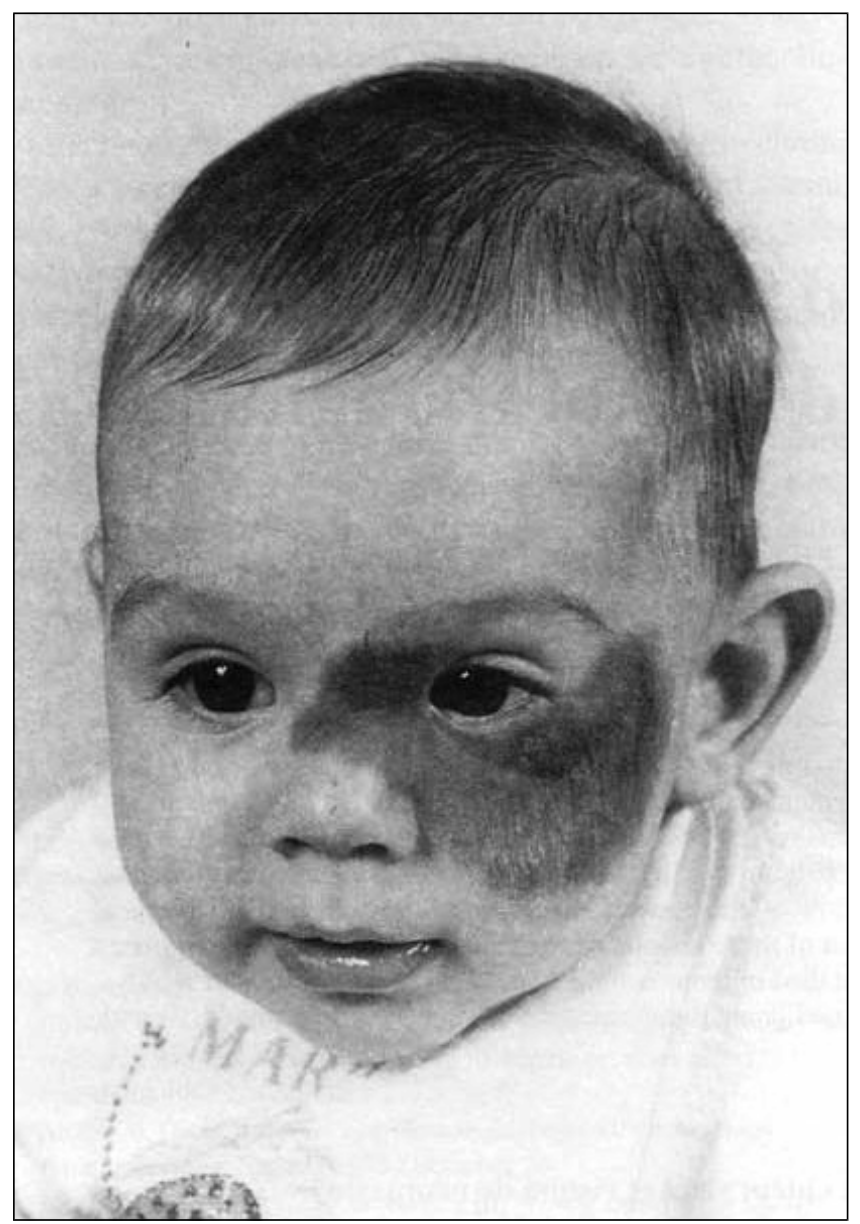

Figure 1) Giant congenital pigmented nevus of the face

\section{METHOD}

Our study includes a retrospective review of children with giant congenital pigmented nevi of the face. Our criteria for 'giant' was a lesion involving a major portion of the face, with size more than $6 \mathrm{~cm}$ in their largest diameter, which precluded complete excision and simple primary closure without the need for grafting or major flap reconstruction (Figure 1). We reviewed the medical records and clinical photographs of children who underwent surgical excision and reconstruction of their giant congenital nevi of the face at the Hospital for Sick Children, Division of Plastic Surgery between January 1980 and December 1991. The study was designed to assess the age distribution of the patients at the time of surgery, extent and location of lesions, operative management, morphological appearance, histological characteristics of the lesions, risk of malignant transformation, and aesthetic results.

\section{RESULTS}

Nineteen children with giant congenital pigmented nevi of the face were included. The ages at the time of surgical intervention ranged from one to 14 years. The majority of the children were between one and seven years old at the time of the first operation (Table 1). Nine were male and 10 were female.
TABLE 1: Ages of children at the time of first surgical intervention

\begin{tabular}{lc}
\hline Age (in years) & Number of patients \\
\hline $1-3$ & 7 \\
$3-5$ & 5 \\
$5-7$ & 5 \\
$7-14$ & 2 \\
Total & 19 \\
\hline
\end{tabular}

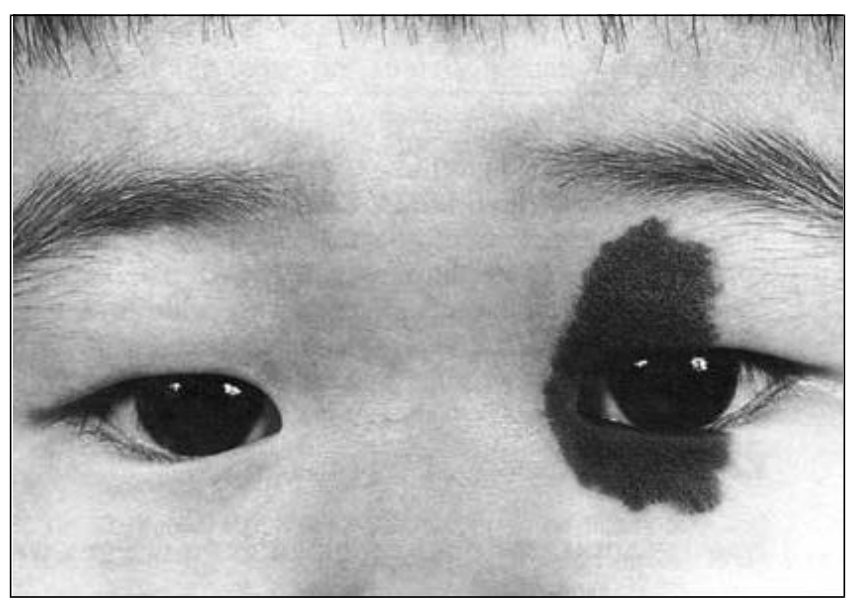

Figure 2) Periorbital nevus

\section{Anatomical location}

All regions of the face were involved. In five patients, the giant nevus involved almost half of the face, including the nasal bridge, eyelids, lower forehead and cheek (Figure 1). In four patients the nevus had a very unusual distribution, involving the eyelids and surrounding the eye to a variable extent (Figure 2). In five patients a large portion of the cheek was involved with variable extension to temporal hairline or the neck, but sparing the eyelids and the nose (Figure 3).

In four patients, a large portion of the forehead was covered by the nevus, with or without involvement of one eyebrow, from the normal hairline approaching the zygomatic arch area (Figure 4).

In only one patient, the nevus involved the chin and anterior portion of the neck, including the submandibular region.

\section{Morphological characteristics}

The appearance of the congenital nevus varied with the age of the patient and, thus, the age of the lesion. At birth and during the first few months of life, the lesion was usually flat, pale tan, and appeared as an irregular, but large café-au-lait spot. It was unevenly pigmented and its colour ranged from brown to black. In the subsequent months of life, the colour gradually became uniformly darker, and coarse hairs became 


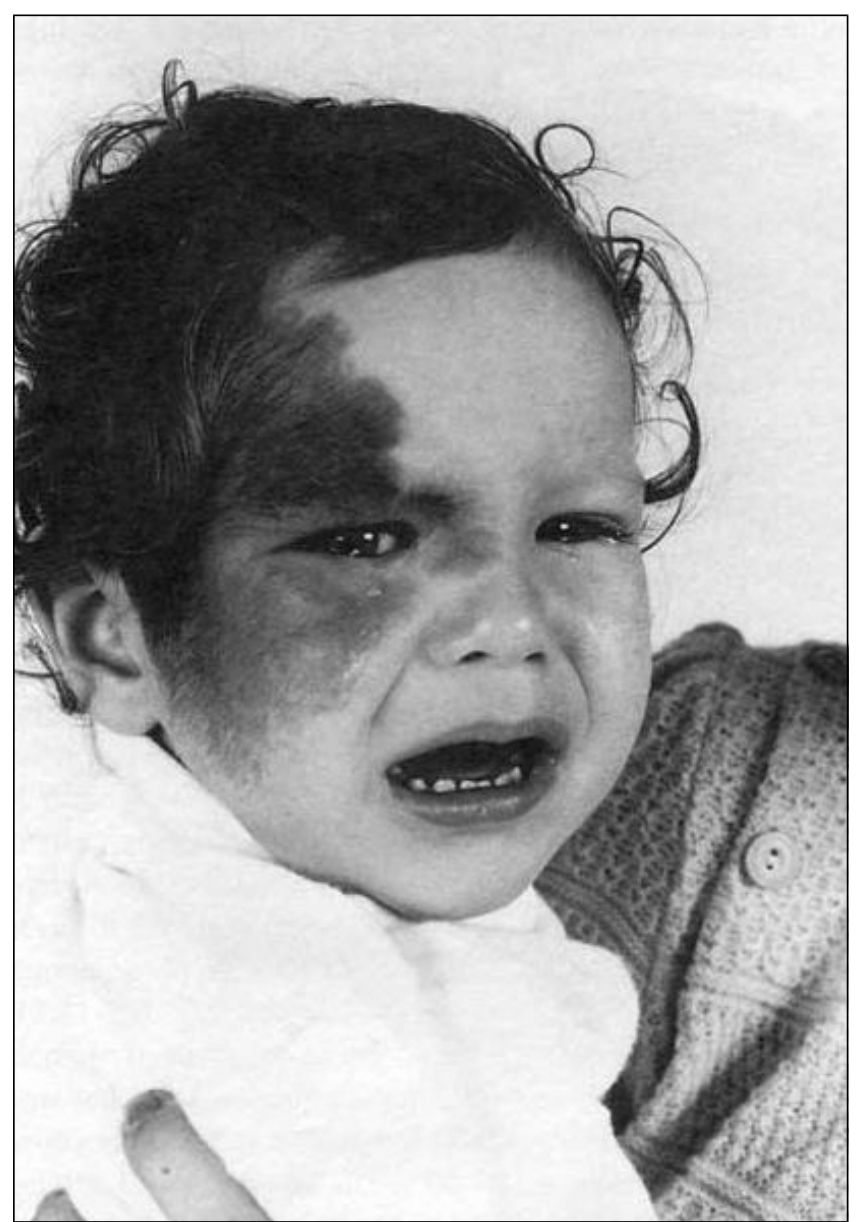

Figure 3) Cheek nevus

more prominent. Later in childhood, the lesion became elevated and demonstrated an increasing number of coarse hairs. The rate and extent of change varied from patient to patient. In their final appearance, the majority of lesions were sharply delineated, without any graduated pigment changes in the adjacent skin.

\section{Operative management}

The objectives in treating giant facial nevi included complete excision and reconstruction with an acceptable aesthetic result, prior to the age at which the child would enter primary school. The type of procedure was determined by the size and location of the nevus. Consideration was given to minimizing the number of procedures required to complete the reconstruction and to minimize the risk of complications with each technique.

All patients were operated upon under general anaesthesia. Surgical excision was undertaken at the junction of the deep and superficial fat just above the fascia. Coverage of the defect was with tissue of optimal colour and texture match. The adjacent skin was used if at all possible.

To accomplish this, tissue expansion of the adjacent normal skin of the face was the main method of reconstruction and was used in 11 patients (58\%) (Figure 5). Four patients were treated using tissue expansion and excision alone, while

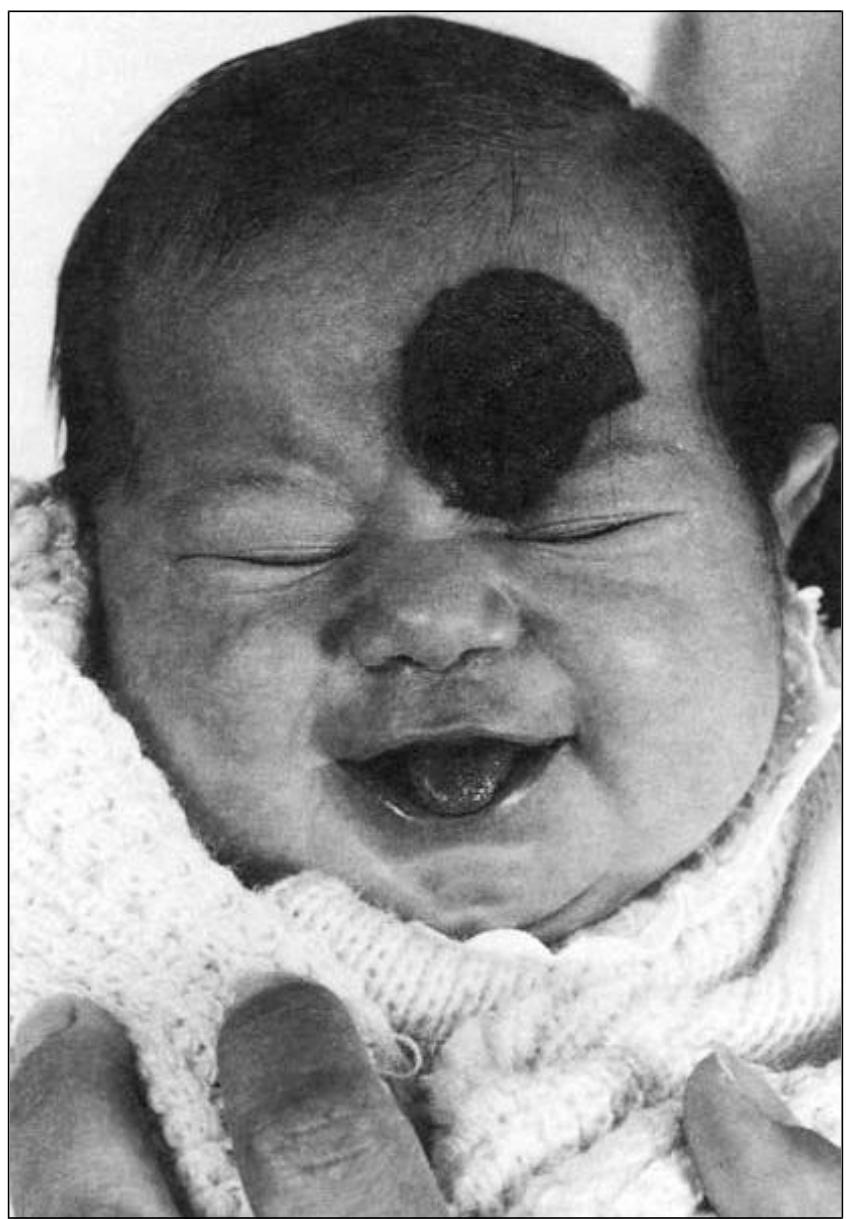

Figure 4) Forehead nevus

the remaining seven required tissue expansion and excision in combination with skin grafting, scar revisions or ectropion repair. Four patients were treated with staged excision of the nevus (21\%); two of these required additional skin grafting of the defect. Another two patients underwent excision of the nevus in one stage and coverage of the defect with a skin graft in a second stage (10.5\%). Finally, two patients underwent excision of the nevus and coverage of the defect with advancement or rotation flaps from the neck and the forehead, respectively (10.5\%) (Table 2). Where skin grafting was required, full-thickness grafts from the postauricular area were used. In some cases where large grafts were required, the postauricular donor defect was covered with a split-thickness skin graft from the buttock. Skin grafting was the method of choice in some areas of the face, specifically the eyelids and the nose. The largest facial nevi in our study, which involved half of the face and the eyelids, were excised using a combination of expanded forehead, neck and cheek flaps plus fullthickness postauricular skin grafts for the nasal dorsum area and the eyelids. Of particular importance was the advancement rotation of the expanded cervical or forehead skin to the cheek area. The extent of the advancement in some patients led to some distortion of the angle of the mouth which was usually temporary. However the slight degree of ectropion 

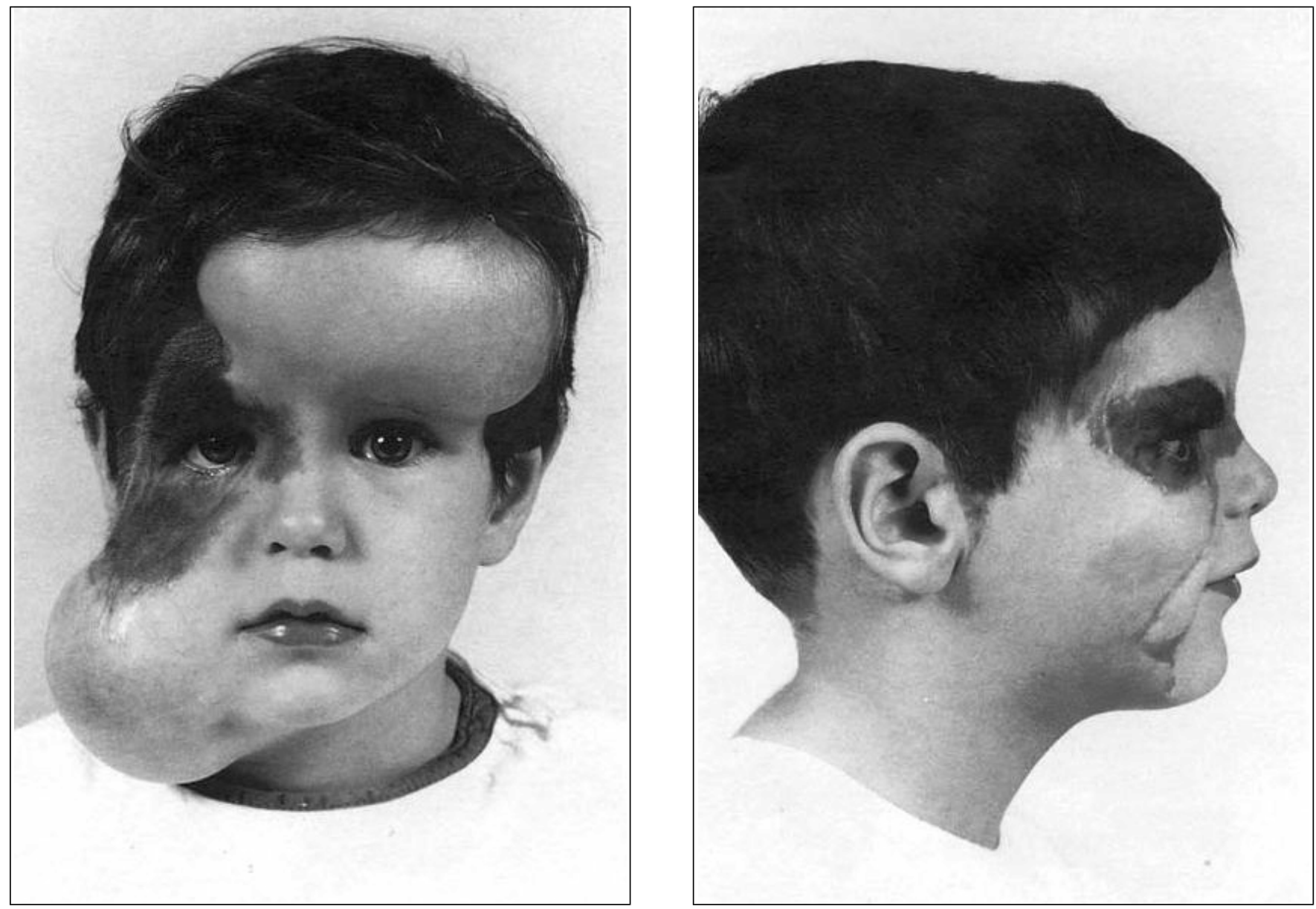

Figure 5) Expanded cheek and forehead flaps for reconstruction of giant congenital facial nevus (left). Result after excision and flap reconstruction (right)

required secondary repair in two patients. The maximum number of expanders used at any operation was three. Only one patient underwent three episodes of expansion and serial excision (a total of seven tissue expanders) before total removal of the nevus. Tissue expansion in this patient began at the age of 16 months.

\section{Complications}

There were no major systemic complications. Four patients suffered local recipient site complications. There were two tissue expander infections, loss of a portion of the skin graft in one patient and hyperpigmentation of the skin graft in one patient. Hypertrophic scarring was a late complication which required revisional surgery in three patients.

\section{Histological characteristics}

Upon histological examination, all were shown to be compound nevi. They contained nests of nevus cells at the epidermal-dermal junction and in the dermis. In many nevi, there was a focal extension of nevus cells around the adnexal elements of the deep dermis. No atypical cells were seen and thus no malignancy was identified in any of our patients except the one child who died of leptomeningeal melanosis.

\section{TABLE 2: Procedures used in the surgical treatment}

Number of patients

\begin{tabular}{lcc} 
1. Tissue expansion + skin grafting & 11 & $(58 \%)$ \\
2. Serial excision + skin grafting & 4 & $(21 \%)$ \\
3. Excision in one stage + skin grafting & 2 & $(10.5 \%)$ \\
4. Excision + coverage with local flaps & 2 & $(10.5 \%)$ \\
Total & 19 & $(100 \%)$ \\
\hline
\end{tabular}

\section{Incidence of malignancy}

There has been a considerable variation in the reported incidence of malignancy in congenital giant nevi. When melanoma does occur in childhood, it bears a very bad prognosis.

Of the 19 patients included in our study, malignant transformation occurred in only one, a two-year-old girl with a congenital giant facial nevus (5.3\%). The nevus occupied a large area of the child's forehead, and was surrounded by many other smaller nevi. Multiple congenital pigmented hairy nevi were also found all over the patient's body. The lesion on the forehead had coarse hair growth and had changed, becoming darker. The nevus was totally excised and the histological examination of the specimen showed a benign com- 
pound nevus. Four months postoperatively, the child was readmitted for regression of developmental milestones and difficulties in speech. A computerized tomographic (CT) scan showed a massive hydrocephalus, and a contrast CT scan showed bright enhancement along the gyri in the sulci and in the basal cisterns. A lumbar puncture biopsy showed melanoma cells and the diagnosis of a disseminated leptomeningeal melanoma associated with her giant hairy nevus syndrome was made. Oncology consultation was obtained and unfortunately this malignancy had no known cure. The patient was transferred closer to home, under palliative symptomatic treatment with morphine, for pain control, and she died one month later.

\section{DISCUSSION}

Giant congenital pigmented nevi of the face create a major cosmetic disfigurement with serious psychological consequences both for patients and their families. Although the cosmetic deformity is of primary importance, the association of these giant congenital pigmented nevi with the development of malignant melanoma suggests that all lesions of this type should be excised (17-20). Complete excision of a giant nevus of the face often involves multiple surgical procedures beginning in infancy and completed in late adolescence (12,21-23). The fact that the depth of these lesions tends to increase from the epidermis to the deep reticular dermis with time led some surgeons to perform dermabrasion during the neonatal period as a means of reducing the number of superficially located nevus cells; however, variable degrees of pigmentation tended to recur and, although the cosmetic result was often improved, dermabrasion did not preclude the risk of malignant transformation because it did not significantly reduce the number of nevus cells (2,24-26). Our results have generally been satisfactory with acceptable aesthetic reconstruction and few minor complications. The facial nevi were

\section{REFERENCES}

1. Walton RG. Pigmented nevi. Pediatr Clin North Am 1971;18:897-923.

2. Zitelli JA, Grant MG, Abell E, et al. Histologic patterns of congenital nevocytic nevi and implications for treatment. J Ann Acad Dermat 1984;11:402-9

3. Rhodes AR. Pigmented birthmarks and precursor melanocytic lesions of cutaneous melanoma identifiable in childhood. Pediatr Clin North Am 1983:30:435-63

4. Castilla EE, Dutra MDG, Orioli-Parreiras IM. Epidemiology of congenital pigmented nevi: Incidence rates and relative frequencies. Br J Dermatol 1981;104:307-15.

5. Rhodes AR, Silverman RA, Harrist TJ, et al. A histologic comparison of congenital and acquired nevomelanocytic nevi. Arch Dermatol 1985;121:1266-73.

6. Alper J, Holmes LB, Mihm MC. Birthmarks with serious medical significance: Nevocellular nevi, sebaceous nevi, and multiple café-au-lait spots. J Pediatr 1979;95:696-700.

7. Greeley PW, Middleton AG, Curtin JW. Incidence of malignancy in giant pigmented nevi. Plast Reconstr Surg 1965;36:26-37.

8. Kopf AW, Bart RS, Hennessey P. Congenital nevocytic nevi and malignant melanomas. J Am Acad Dermatol 1979;1:123-30.

9. Mark GJ, Mihm MC, Liteplo MG, et al. Congenital melanocytic nevi of the small and garment type. Human Pathol 1973;4:395-418. totally excised in all our patients and the procedures used were well tolerated by both the children and their parents. The best aesthetic results were achieved with tissue expansion, which was the primary method of reconstruction (Figure 5).

There is now considerable evidence that malignancy can arise within giant congenital nevi, and that the risk is greater in the larger ones (10). In the literature, estimates of the incidence of such malignancy varies widely, ranging all the way from $2 \%$ to $42 \%$ (27). Despite this lack of precision, however, the risk of malignant transformation is age-related and most of the reported malignancies occurred in children. When the lesion involves the head and neck, a relation between giant congenital nevus and leptomeningeal melanocytosis has been reported. Because the meninges are embryologically of neural crest origin, like the pigment cells of the skin, it is possible that both meninges and skin could have hamartomatous melanocytes or nevocytes. In these benign nevocytes of the meninges, malignant degeneration can occur, with impairment of the cerebrospinal fluid absorption, causing hydrocephalus and seizures. In our study, one patient demonstrated disseminated leptomeningeal melanoma associated with her giant congenital nevus of the face. The incidence in this review is $5.3 \%$. Although an accurate incidence of malignant transformation has not been determined, the risk of malignancy in the congenital giant nevi must be considered in the overall management.

\section{CONCLUSION}

The cosmetic deformity associated with giant congenital facial nevi and the life-threatening potential for malignant transformation are considerable; therefore, we recommend the complete early excision of these lesions.

Our study showed that acceptable reconstruction following excision can be achieved with tissue expansion of the normal adjacent skin of the face, in combination with skin grafting.

10. Kaplan EN. The risk of malignancy in large congenital nevi. Plast Reconstr Surg 1974;53:421-8.

11. Lanier VC, Pickrell KL, Georgiade NG. Congenital giant nevi: Clinical and pathological considerations. Plast Reconstr Surg 1976;58:48-54.

12. Pilney FT, Broadbent TR, Woolf RM. Giant pigmented nevi of the face: Surgical management. Plast Reconstr Surg 1967;40:469-74.

13. Hoffman HJ, Freeman A. Primary malignant leptomeningeal melanoma in association with giant hairy nevi. J Neurosurg 1967;26:62-71.

14. Reed WB, Becker SW, Becker SW Jr, et al. Giant pigmented nevi, melanoma and leptomeningeal melanocytosis. Arch Dermatol 1955;19:100.

15. Silverberg GD, Kadin ME, Dorfman RF, et al. Invasion of the brain by cellular blue nevus of the scalp. Cancer 1971;27:349-55.

16. Fox H, Emery JL, Goodbody RA, et al. Neurocutaneous melanosis. Arch Dis Childhood 1964;39:508-16.

17. Weidner N, Flanders DJ, Jochimsen PR. Neurosarcomatous malignant melanoma arising in a neuroid giant congenital melanocytic nevus. Arch Dermatol 1985;121:1302-6.

18. Workman ML, Kaye VN, Anderson PM, et al. Malignant melanoma with evidence of maturation arising from a giant congenital nevocellular nevus. Ann Plast Surg 1992;28:381-5.

19. Lorentzen M, Pers M, Bretteville-Jensen G. The incidence of malignant 
transformation in giant pigmented nevi. Scand J Plast Reconstr Surg 1977;11:163-7.

20. Trozak DJ, Rowland WD, Hu F. Metastatic malignant melanoma in prepubertal children. Pediatrics 1975;55:191-204.

21. Bauer BS, Vicari FA. An approach to excision of congenital giant pigmented nevi in infancy and early childhood. Plast Reconstr Surg 1988;82:1012-21.

22. Arons MS, Hurwitz S. Congenital Nevocellular Nevus: A review of the treatment controversy and a report of 46 cases. Plast Reconstr Surg 1983;72:355-65.
23. Converse JM, Guy CL, Molenaar A. The treatment of giant hairy pigmented nevi of the face. Br J Plast Surg 1969;22:302-8.

24. Walton RG, Jacobs AH, Cox AJ. Pigmented lesions in newborn infants. Br J Dermatol 1976;95:389-96.

25. Johnson HA. Permanent removal of pigmentation from giant hairy nevi by dermabrasion in early life. Br J Plast Surg 1977;30:321-3.

26. Miller CJ, Becker DW Jr. Removing pigmentation by dermabrading nevi in infancy. Br J Plast Surg 1979;32:124-6.

27. Dellon AL, Edelson RL, Chretien PB. Defining the malignant potential of the giant pigmented nevus. Plast Reconstr Surg 1976;57:611-8. 